\title{
First-pass stress perfusion MR Imaging findings of apical hypertrophic cardiomyopathy: with relation to LV wall thickness and late Gadolinium-enhancement
}

Jin Young Yoo ${ }^{2 *}$, Eun Ju Chun', Yeo-Koon Kim', Sang $\|$ Choi $^{1}$

From 18th Annual SCMR Scientific Sessions

Nice, France. 4-7 February 2015

\section{Background}

To evaluate the prevalence and pattern of perfusion defect (PD) on first-pass stress perfusion MR imaging in relation with the degree of left ventricular hypertrophy (LVH) and late gadolinium-enhancement (LGE) in patients with apical hypertrophic cardiomyopathy (APH).

\section{Methods}

Cardiac MR imaging with first-pass stress perfusion, cine, and LGE sequence was performed in 26 patients with APH from January 2008 to December 2012. We analyzed a total of 416 segments for LV wall thickness on end-diastolic phase of cine images, and evaluated the
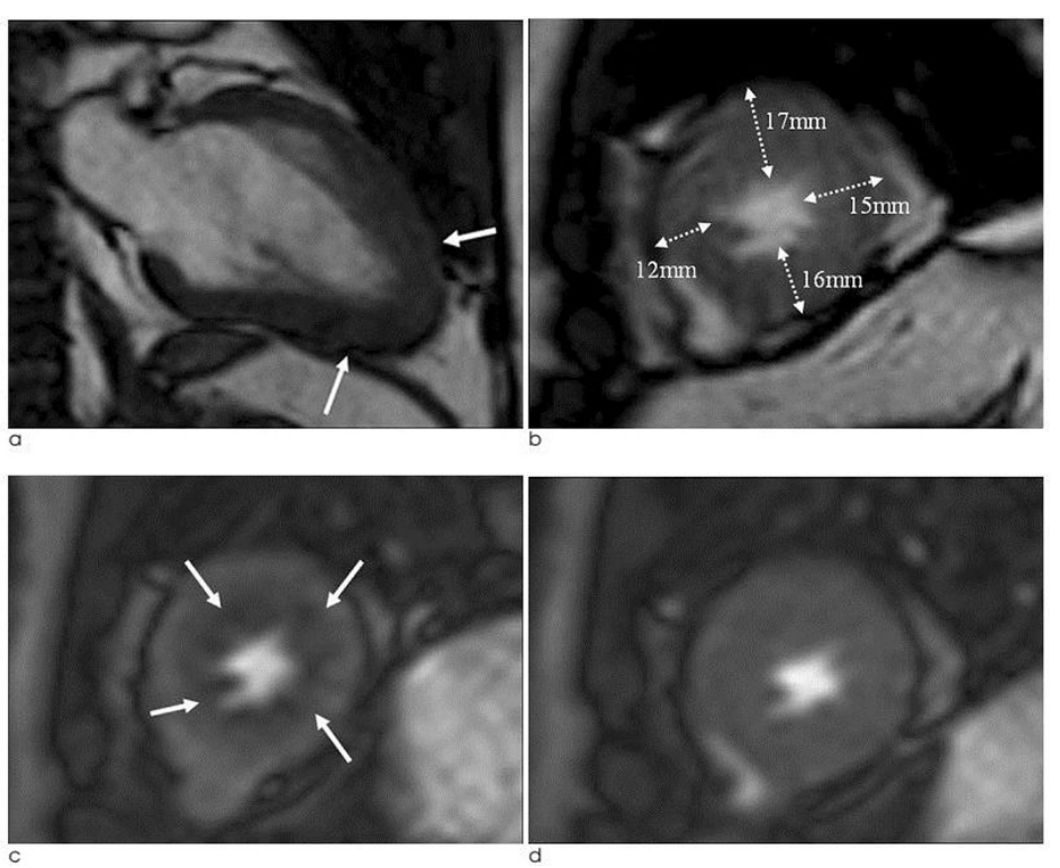

Figure 1 A 45-year old male patients with angina pain who visited to emergency room was confirmed as apical HCM by typical ECG and echocardiographic findings, and he performed CMR for risk stratification. a. Two-chamber cine image shows apical wall thickening with typical 'spade of ace' sign (arrows). b. Short-axis cine image shows LVH at apical anterior, lateral and inferior wall (NHS of 3, NCH-3). c, d. First-pass stress perfusion (c) and rest perfusion (d) show reversible ring of subendocardial perfusion defect (arrows) at whole apical layer.

\footnotetext{
${ }_{2}^{2}$ Radiology, Kangbuk Samsung Hospital, Seoul, Korea (the Republic of
} Full list of author information is available at the end of the article 
Table 1 Independent Predictors for Perfusion Defect

\begin{tabular}{|c|c|c|c|c|c|c|c|c|}
\hline & $\begin{array}{l}\text { For overall perfusion } \\
\text { defect }\end{array}$ & & $\begin{array}{c}\text { For ring of subendocardial } \\
\text { perfusion defect }\end{array}$ & & & & & \\
\hline & & $\begin{array}{c}95 \% \\
\mathrm{Cl}\end{array}$ & & & $\begin{array}{c}95 \% \\
\mathrm{Cl}\end{array}$ & & & \\
\hline & $H R$ & upper & lower & $\begin{array}{c}\mathrm{p}- \\
\text { value }\end{array}$ & $\mathrm{HR}$ & upper & lower & $\begin{array}{c}\mathrm{p}- \\
\text { value }\end{array}$ \\
\hline Age (years) & 0.98 & 0.90 & 1.08 & 0.983 & 1.00 & 0.92 & 1.08 & 0.960 \\
\hline Sex & 0.80 & 0.07 & 8.91 & 0.856 & 4.40 & 0.42 & 46.26 & 0.217 \\
\hline BMI $\left(\mathrm{kg} / \mathrm{m}^{2}\right)$ & 1.11 & 0.73 & 1.69 & 0.633 & 1.18 & 0.81 & 1.72 & 0.378 \\
\hline Hypertension & 1.50 & 0.21 & 10.82 & 0.688 & 1.20 & 0.21 & 6.88 & 0.838 \\
\hline Diabetes & 0.01 & 0.00 & - & 0.999 & 2.60 & 0.21 & 32.90 & 0.461 \\
\hline Current smoker & 0.64 & 0.09 & 4.89 & 0.643 & 0.53 & 0.10 & 2.98 & 0.474 \\
\hline Hypercholesterolemia & 0.86 & 0.12 & 6.01 & 0.877 & 6.00 & 0.92 & 39.19 & 0.061 \\
\hline $\begin{array}{l}\text { Family history of sudden cardiac death } \\
\text { or HCM }\end{array}$ & 0.10 & 0.01 & 1.49 & 0.095 & 5.00 & 0.04 & 6.55 & 0.597 \\
\hline Med_aspirin & 0.33 & 0.05 & 2.21 & 0.255 & 1.25 & 0.24 & 6.63 & 0.793 \\
\hline Med_antithrombotic drug & 0.01 & 0.00 & - & 1.000 & 0.01 & 0.00 & - & 1.000 \\
\hline Symptom & 0.75 & 0.11 & 5.11 & 0.769 & 0.78 & 0.16 & 3.80 & 0.756 \\
\hline Typical angina including syncope & 3.18 & 0.30 & 33.26 & 0.334 & 6.60 & 0.97 & 44.93 & 0.054 \\
\hline Ejection Fraction (\%) & 0.99 & 0.86 & 1.14 & 0.883 & 1.08 & 0.95 & 1.22 & 0.260 \\
\hline LV mass (g) & 1.01 & 0.99 & 1.03 & 0.322 & 1.01 & 1.00 & 1.02 & 0.203 \\
\hline Maximal LV wall thickness (mm) & 1.97 & 1.05 & 2.43 & $0.029^{*}$ & 1.50 & 1.06 & 2.13 & $0.021^{*}$ \\
\hline$\overline{L G E}$ & 3.00 & 0.45 & 19.93 & 0.255 & 3.75 & 0.59 & 23.87 & 0.162 \\
\hline $\mathrm{NHS}$ & 1.82 & 1.01 & 3.30 & $0.048^{*}$ & 1.40 & 0.99 & 1.97 & 0.056 \\
\hline AHS-2 & 5.67 & 0.75 & 42.58 & 0.092 & 2.00 & 0.30 & 13.51 & 0.477 \\
\hline AHS-3 & 3.71 & 0.54 & 25.59 & 0.183 & 9.00 & 1.39 & 58.44 & $0.021^{*}$ \\
\hline
\end{tabular}

number of hypertrophied segment and number of consecutive hypertrophied segment $(\mathrm{NCH})$. We assessed the presence or absence of PD and LGE from all patients. If there was $\mathrm{PD}$, we subdivided the pattern into sporadic (sporadic-PD) or ring (ring-PD). Using univariate logistic method, we obtained the independent predictor for presence of overall PD and ring-PD.

\section{Results}

PD on stress perfusion MRI was observed in 20 patients (76.9\%), 12 of them (60\%) showed ring-PD. Maximal LV wall thickness and number of hypertrophied segment were independent predictors for overall PD (all, p < $0.05)$. $\mathrm{NCH}$ with more than 3 segments was an additional independent factor for ring-PD. However, LGE was not statistically related with $P D$ in patients with $\mathrm{APH}$.

\section{Conclusions}

About three quarters of the patients with APH showed $\mathrm{PD}$, most of them represented as ring-PD. LVH degree or distribution was related with pattern of PD, however,
LGE was not related with PD. Therefore, the clinical significance of PD in the patients with APH seems to be different from those with non-APH, and further comparison study between the two groups should be carried out.

\section{Funding}

N/A.

\section{Authors' details}

${ }^{1}$ Radiology, Seoul National University Bundang Hospital, Seongnam-si, Korea (the Republic of. ${ }^{2}$ Radiology, Kangbuk Samsung Hospital, Seoul, Korea (the Republic of.

Published: 3 February 2015

doi:10.1186/1532-429X-17-S1-Q66

Cite this article as: Yoo et al:: First-pass stress perfusion MR Imaging findings of apical hypertrophic cardiomyopathy: with relation to LV wall thickness and late Gadolinium-enhancement. Journal of Cardiovascular

Magnetic Resonance 2015 17(Suppl 1):Q66. 